\title{
Creating a Chain of Teaching and Learning Support: Documenting the Effects of the Teaching Development Graduate Assistant Program
}

\author{
Kristin A. Force \\ York University
}

This essay will demonstrate that the teaching development graduate assistant (TDGA) program at the Centre for the Support of Teaching, York University, creates a chain of teaching support between the TDGA coordinator, TDGAs, teaching assistants, faculty, and undergraduate students within a heavily populated university. The importance of teaching and learning workshops for graduate students with minimal university teaching experience will be demonstrated. The methodology for this project includes documenting personal experiences as the TDGA coordinator and informal interviews with TDGAs, discussing their workshops and other activities.

\section{Introduction}

T eaching and learning centres at Canadian universities are continually developing activities and programs to support graduate students embarking upon university teaching. An example of this support lies in teaching assistant (TA) training programs. Over the years, scholars have presented a number of strategies for TA training and development in higher education (Nyquist, 1991; Nyquist \& Wulff, 1996). Others have created reference guides for university teaching assistants (Lambert, Lane Tice, \& Featherstone, 1996; Lane Tice, Jackson, Lambert, \& Englot, 2005; Curzan
\& Damour, 2006). Recently, Ross and Dunphy (2007) compiled a resource for anyone who works with TAs, consisting of various techniques for workshops or classroom sessions. Different centres have taken various approaches to TA development. For example, the teaching support centre at the University of Western Ontario offers a twoand-a-half day seminar at various times throughout the year for TAs in instructional and practical training (TATP, 2009). Ryerson University's faculty of arts offers an arts teaching assistant development program consisting of TA and peer 
development workshops that leads to a general or advanced certificate (Arts Teaching, 2009). These programs are facilitated by experienced graduate students and allow TAs to interact with their peers. The purpose of this essay is to outline the teaching development graduate assistant (TDGA) program at York University, emphasizing the role and importance of TA training programs in Canadian universities.

The TDGA program is a joint project of the Centre for the Support of Teaching (CST) and the faculty of graduate studies (TDGA Program, 2009). Its goal is to provide teaching and learning support to TAs. This program is coordinated by the CST, complementing its programming for TA teaching development with discipline-specific programming to support teaching and learning within departments. In the majority of graduate programs, the director assigns two $\mathrm{PhD}$ students to the TDGA position who have a minimum of two years of teaching experience at the post-secondary level, along with a faculty liaison who is responsible for assisting TDGAs within the department. The graduate students assigned to this role are responsible for organizing and facilitating teaching development workshops and discussion groups, and providing peer support to new and experienced TAs. They are responsible for completing 135 hours of teaching and learning support to the department (the equivalent of one half a TA-ship). In these hours, the TDGA is responsible for organizing at least five hours of discipline-specific workshops and developing teaching resources for their department with a year-end report of their activities. They also attend a number of meetings over the course of the year, as well as the CST's annual TA Day. The mandatory five hours of workshops that the TDGAs must facilitate is required as the discipline-specific component of the university teaching practicum or the University Teaching Practicum (UTP) (TDGA Program, 2009).

Since I had held a TDGA position in the music department for two years and was extremely interested in the program, the academic director of the CST, Dr. Ros Woodhouse assigned me to the TDGA coordinator position for 2007-8. In this inaugural role, my main objective was to create a greater awareness of the program, and a sense of community among TDGAs. In the past, they would typically run five hours of workshops and attend two meetings with minimal interaction among themselves and little communication with the CST. I realized that this was a major problem within the program. Therefore, with the support of the centre, I attempted to create a TDGA community. As a result, the TDGAs became more involved in and enthusiastic about the program by attending numerous meetings and discussion groups, and communicating through the online TDGA Moodle site. In addition, I met with them on an individual basis to check on their progress and provide additional support. Through these strategies, many TDGAs ran more than five hours of workshops, created teaching and learning resources for their departments, utilized the Moodle site, and overall, became more involved in the program.

I facilitated a number of meetings throughout the year with the support of the CST directors and graduate teaching associates. These featured: a faculty liaison and TDGA luncheon, a welcome and orientation meeting, meetings on getting started, achievements and challenges, identifying the existing and emergent needs of TAs, and writing the year-end report. In the initial meetings, I provided methods of initiating their programs for the year and ideas for workshops. Based on Brooks-Harris and StockWard's (1999) research on workshop construction, TDGAs were encouraged to: a) understand their TAs; b) develop comprehensive workshops and facilitate them in order to promote active learning ( $\mathrm{p}$. $10-11)$; c) assess the needs and interests of TAs in addition to considering their own experiences; d) survey graduate students in their departments to obtain ideas for workshops; and e) become familiar with the university teaching practicum in order to meet TAs' needs for completing the requirements.

At first, I provided the TDGAs with activities they should consider including in their plan for the year, and then I outlined a sample work plan, encouraging them to implement a variety of activities. They were also provided with a list of possible alternate activities and events, including organizing a departmental orientation for new TAs, developing a teaching manual or newsletter for their department, 
coordinating a mentorship program matching new TAs to senior graduate students, holding a professional development workshop, creating a departmental TA directory, developing a departmental teaching resource library, developing a website for TAs, and instituting departmental TA teaching awards (TDGA Manual, 2009). I also focused on the importance of connecting research in their disciplines to teaching (Jenkins, Breen, Lindsay \& Brew, 2003; Brew, 2006). For example, the music department has an annual fieldwork equipment workshop, focusing on how to use audio-visual equipment for ethno-musicological research as well as for teaching. In addition, the TDGA from the humanities department incorporates research on political refugees and multiculturalism to address issues of diversity and human rights in the workshops and the classroom.

Since York University is a heavily populated institution, and academic life is at times a socially isolating experience (Shaw, 2004), I wanted to connect with the TDGAs and find out how they were doing. I met with a representative from dance, music, humanities, education, chemistry, and biology. I began this session by asking them informally if they were having a good experience in their role as a TDGA. I then asked a series of questions designed to determine whether they were actively involved in the program. From the results, these TDGAs were running workshops on a regular basis and participating in other teaching related activities, including developing newsletters and reviews, conducting informal discussions with TAs, creating TA resources, meeting with TAs on an individual basis, learning Moodle, talking to faculty about the program, attaching TDGA events to other department meetings, and discussing the requirements of the UTP with TAs and faculty. In addition, the biology representative facilitated a departmental TA Day.

In the workshops, TDGAs relayed a number of different teaching strategies. The representative from the dance department focused on fostering creative expression, group interaction, and new improvisation strategies. The music TDGA demonstrated how TAs could integrate listening examples into their tutorials. The TDGA from humanities focused on teaching critical skills and generating discussion, in addition to developing a blog incorporating academic and life experiences to highlight the transferability of skills for academics. The education representative stated that the workshops were most successful if structured around group learning. As a result, they were simple, practical, informal, and based on TAs' own experiences. The chemistry TDGA focused on techniques for running effective labs and the importance of teaching development in the sciences, while the biology representative felt that the workshops were most effective if open-ended questions were presented. TDGAs employed a wide range of techniques for the workshops and classroom that they felt were most applicable to their disciplines.

In previous years, there was minimal communication between TDGAs. In order to initiate an online community, I encouraged them to post their upcoming workshops on the Moodle site. They could then check for workshops in other departments and attend those that were applicable. Of the 36 workshops posted by April 2008, 27.8\% dealt with general teaching and learning practice, $27.8 \%$ with professional development, $19.4 \%$ classroom engagement, $8.3 \%$ technology in the classroom, $5.6 \%$ essays and writing, 5.6\% marking and grading, $2.8 \%$ diversity issues, and $2.8 \%$ reflective practice. The above categories reflect TAs' needs, as TDGAs were required to survey them for workshop ideas before organizing any sessions. The workshops in the general teaching and learning category were organized for TAs who needed advice and guidance in teaching, and included training sessions, foundations and general education workshops, and tips for survival and success in specific disciplines. The professional development workshops focused on making the transition from TA to course director, designing and implementing a teaching philosophy, how to design a course, public speaking and presentations, preparing teaching dossiers, publishing, and searching for academic positions. Since this was one of the largest categories, it is evident that TAs today are seeking advice and information on how to move forward in their fields. Recent scholarship has indicated that academics need more guidance than ever as knowledge is constantly changing in higher education and traditional forms of pedagogy are now challenged (Welch, 2005). 
The TDGA workshops provide useful teaching techniques and strategies for TAs specific to their disciplines, but most importantly they provide an opportunity for them to openly discuss their questions and concerns, and receive support from their peers, especially in a large institution. They also discuss how to actively engage undergraduates, as student engagement in the twenty-first century is becoming increasingly important (Harper \& Quaye, 2008). The interviewed TDGAs stated that their undergraduate students were engaged and involved in their classes.

In summary, TA training programs should be an integral component of graduate studies. TAs heavily depend on the university, and we should respond to their needs and experiences (Andrews, 1985). The TDGA program at York University allows graduate students to develop organizational and communication skills through the facilitation of workshops and other teaching-related activities that are beneficial for future academic or non-academic positions. They learn how to address specific issues within their departments, and communicate with faculty, TAs, and students. They are given the opportunity to work closely with the faculty through department committees, and become more familiar with the university governance structure. Interested faculty members often discuss their teaching strategies with TAs and offer suggestions. Many TAs become more involved in the CST's teaching and learning workshop series and register for the university teaching practicum. Overall, the TDGA program creates a chain of teaching and learning support and guidance for graduate students preparing to teach in a university.

\section{References}

Andrews, J.D.W. (1985). Strengthening the teaching assistant faculty. San Francisco, CA: JosseyBass.

Brew, A. (2006). Research and teaching: Beyond the divide. New York, NY: Palgrave MacMillan.

Brooks-Harris, J.E. \& Stock-Ward, S.R. (1999). Workshops: Designing and facilitating experiential learning. Thousand Oaks, CA: Sage Publications.

Teaching development graduate assistant [TDGA] manual. (2009). Retrieved April 7, 2009, from the Centre for the Support of Teaching, York University Website: http:// www.yorku .ca /cst/grads/tdga-manual/ index.html

Teaching development graduate assistant [TDGA] program. (2009). Retrieved April 7, 2009, from the Centre for the Support of Teaching, York University Website: http:// www. yorku.ca/cst/grads/tdga.html

Curzan, A. \& Damour, L. (2006). First day to final grade: A graduate student's guide to teaching. Ann Arbor, MI: University of Michigan Press.

Harper, S. \& Quaye, S.J. (2008). Student engagement in higher education: Theoretical perspectives and practical approaches for diverse populations. Milton Park, Abingdon, Oxford:Routledge.

Jenkins, A., Breen, R., Lindsay, R., \& Brew, A. (2003). Reshaping teaching in higher education: Linking teaching with research. Milton Park, Abingdon, Oxford: Routledge.

Lambert, L.M., Lane Tice, S., \& Featherstone, P.H. (1996). University teaching: A guide for graduate students. Syracuse, NY: Syracuse University Press.

Lane Tice, S., Jackson, N., Lambert, L.M., \& Englot, P. (2005). University teaching: A reference guide for graduate students and faculty. Syracuse, NY: Syracuse University Press.

Nyquist, J.D. (1991). Preparing the professoriate of tomorrow to teach: Selected readings in 
TA training. Dubuque, IA: Kendall/Hunt Publishing Company.

Nyquist, J.D. \& Wulff, D.H. (1996). Working effectively with graduate assistants. Thousand Oaks, CA: Sage Publications.

Ross, C. \& Dunphy, J. (2007). Strategies for teaching assistant and international teaching assistant development. San Francisco, CA: Jossey-Bass.

Arts teaching assistant development program. (2009). Retrieved April 7, 2009, from Ryerson Faculty of Arts, Ryerson University Website: http://www.arts.ryerson.ca/artsta

Shaw, V.N. (2004). Career making in postmodern academia: Process, structure, and consequence. Lanham, MD: Hamilton Books.

The teaching assistant training program [TATP].

(2009). Retrieved April 7, 2009, from the Teaching Support Centre, University of Western Ontario Website: http://www.uwo. ca /tsc/teaching_assistant_program.html

Welch, A.R. (2005). The professoriate: Profile of a profession. New York, NY: Springer.

\section{Biography}

Kristin A. Force is currently a research assistant at the Centre for the Support of Teaching at York University, Toronto, Ontario, where she recently completed her doctoral degree in musicology. Her current research focuses on the scholarship of teaching and learning at Australian universities. 